\title{
Increased Risk of the APOB rs11279109 Polymorphism for CHD among the Kuwaiti Population
}

\author{
Suzanne A. Al-Bustan, ${ }^{1}$ Fatma G. Ismael, ${ }^{1}$ Ahmad Al-Serri, ${ }^{2}$ and Ibrahim Al-Rashdan ${ }^{3}$ \\ ${ }^{1}$ Department of Biological Sciences, Faculty of Science, Kuwait University, Kuwait City, Kuwait \\ ${ }^{2}$ Department of Pathology, Human Genetics Unit, Faculty of Medicine, Kuwait University, Kuwait City, Kuwait \\ ${ }^{3}$ Department of Medicine, Faculty of Medicine, Kuwait University, Kuwait City, Kuwait
}

Correspondence should be addressed to Suzanne A. Al-Bustan; s.albustan@ku.edu.kw

Received 2 August 2017; Revised 4 October 2017; Accepted 22 October 2017; Published 6 December 2017

Academic Editor: Roberta Palla

Copyright (C) 2017 Suzanne A. Al-Bustan et al. This is an open access article distributed under the Creative Commons Attribution License, which permits unrestricted use, distribution, and reproduction in any medium, provided the original work is properly cited.

\begin{abstract}
Background. Coronary heart disease (CHD) is among the leading causes of death in Kuwait. This case-control study investigated the genetic association of $A P O B$ rs11279109 with CHD in Kuwaitis. Methods. The polymorphism was genotyped in 734 Kuwaiti samples by direct amplification. Statistical analysis with genetic modeling was used to assess its association with CHD. Results. A statistically significant association $(P<0.001)$ between the rs11279109 DD genotype (OR: 2.43 , CI: 1.34-4.41) with CHD was observed. A codominant genetic model revealed a 2.69 risk increase (CI: $1.57-4.61)$ for the $D D$ genotype $(P=0.009)$ independent of age, sex, BMI, smoking, hypercholesterolemia, and ethnicity suggesting APOB rs11279109 as an indicator for the increased risk of CHD. Conclusion. The DD genotype may explain molecular mechanisms that underline increased LDL oxidation leading to arthrosclerosis. The findings emphasize the need to identify genetic markers specific to the CHD patient ethnic group in order to improve prognosis and help in early diagnosis and prevention.
\end{abstract}

\section{Background}

Coronary heart disease (CHD) is the leading cause of death and disability-adjusted life years (DALYs) worldwide [1] accounting for about $39.5 \%$ of all deaths in Kuwait $[2,3]$. $\mathrm{CHD}$ results from poor circulation of blood and oxygen as a result of the narrowing of the small blood vessels. The manifestation of CHD is usually presented with myocardial infarction and/or angina, due to coronary atherosclerosis. Extensive studies $[4,5]$ have demonstrated that the interaction between various environmental factors and specific genetic polymorphisms leads to CHD. However, the exact etiology and molecular mechanisms remain unresolved. The association of advanced age, sex, nutrition, smoking, metabolic syndrome, and physical inactivity has been studied extensively and documented in the Kuwaiti population $[2,6,7]$. Limited studies have focused on the association of genetic factors with $\mathrm{CHD}$ in either the Kuwaiti population [8-10] or among Arab ethnic groups in general [11].
During the past decades, genetic association studies and genome-wide association studies have focused on the identification and characterization of genetic polymorphisms that may increase the susceptibility to CHD in the presence of one or more risk factors and in specific ethnic groups and/ or populations [12-19]. The highly implicated risk factors for CHD pathogenesis are increased levels of cholesterol and low-density lipoproteins (LDL) and/or decreased levels of high-density lipoproteins (HDL). Lipids are well known to play a major role in the development of type 2 diabetes mellitus (T2DM), obesity, and hypertension, collectively known as the metabolic syndrome that subsequently could result in heart disease. Therefore, it is important to characterize genes responsible for lipid transport and metabolism including the Apolipoprotein family. Mutations in these polymorphic genes may alter the protein function thereby affecting the transport and metabolism of lipoproteins. Such variants may also interact with common risk factors leading to atherosclerosis and consequently to the manifestation of CHD. One of these genes is $A P O B$. 
There are two forms of the ApoB protein, apoB-100 and apoB-48, resulting from tissue-specific alternative splicing. ApoB-100 consists of 4560/4563-amino acids including a 27-residue signal sequence. The mature protein forms part of chylomicrons and very low-density lipoproteins (VLDL) that are synthesized during lipoprotein metabolism; in addition, it contains the binding site for the uptake of LDL by its receptor [20]. The human $A P O B$ gene, localized to chromosome 2 p23-24, is $43 \mathrm{~Kb}$ comprising 29 exons and 28 introns [21]. Numerous polymorphisms at the $A P O B$ gene locus have been reported and studied [19, 22-26]. One commonly studied polymorphism is an insertion/deletion variant (rs11279109) within the promoter region coding for the signal peptide. There are two common alleles: an insertion allele (I, sp27) which codes for the 27-amino acid signal peptide and a deletion allele (D, sp24) which codes for the 24-amino acid signal peptide lacking the hydrophobic leucine-alanine-leucine residues [27]. The most commonly reported genotype is II with variable frequencies in different populations [28-31].

Conflicting results have been reported with regard to the association of this polymorphism with $\mathrm{CHD}$, and very limited studies have been reported in the Kuwaiti population [8-10]. Therefore, this study aimed to analyze the genetic association of $A P O B$ rs11279109 with the increased risk of developing CHD. The Kuwaiti population is heterogeneous with two major ethnic groups, Arabs including Bedouin Arabs and Persians, while the rest are an admix [26]. In this paper, genetic association of $A P O B$ rs11279109 with the increased risk to CHD in Kuwaiti Arabs is reported.

\section{Methods}

2.1. Sample Description and Diagnostic Criteria. Blood samples were collected from a total of 734 Kuwaiti participants including $371 \mathrm{CHD}$ patients and 363 controls that were matched as closely as possible based on age and sex. Patient's samples $(n=371)$ were obtained from patients who were routine visitors to the outpatient clinics for follow-ups at Kuwait Chest Hospital, Al-Amiri Hospital, and Mubarak Hospital. The CHD patients included 246 males and 126 females with a mean age of onset of CHD of 48.4 years. Clinical diagnosis was provided from the medical records. The inclusion criteria were based on the medical history of the presence of typical chest pain, echocardiogram and previous history of MI, coronary angioplasty, or percutaneous transluminal coronary angioplasty (PTCA), and coronary artery bypass grafting (CABG). The controls $(n=363)$ consisted of a random sample of Kuwaiti patients who were visiting the hospital for a routine checkup and had medical records. The inclusion criteria were being devoid from any type of cardiovascular diseases and having a normal coronary artery with no evidence of plaque or peripheral vascular disease as confirmed by angiography, medical profile, or previous medical history as documented in their medical records. The controls were matched based on sex and age $( \pm 2$ years) and included 228 males and 135 females with a mean age of 54.2 years. This study has been approved by the local ethical committee at Kuwait
University as well as the Ministry of Health Ethical Board, Kuwait. The sample and medical data collection protocol and informed consents used were in accordance to the modified Helsinki guidelines of 1975 and revised in 2000. Informed consent from each participant in this study was obtained.

2.2. Assessment of Risk Factors to CHD. For each sample, information regarding age, age of onset of $\mathrm{CHD}$, medical history of metabolic disorders, lipid profile, BMI (calculated as body weight (kilogram) divided by height (meter) squared $\left.\left(\mathrm{kg} / \mathrm{m}^{2}\right)\right)$, smoking, and family history were documented with a standardized questionnaire for each patient as well as for each of the control samples. Medical history for hypertension, dyslipidemia, and T2DM were documented based on medical records, medication, and filed reports. In addition, ethnicity was documented based on recording parental origins both paternally and maternally dating back at least four generations. Informed consent was obtained from all the volunteers. All data was logged into the SPSS software (Version 22; SPSS Inc., Chicago, IL, USA) for statistical analysis and association to CHD and $A P O B$ rs11279109 polymorphism. Modifiable (BMI, dyslipidemia, T2DM, hypertension, and smoking) and nonmodifiable factors (age, sex, family history, and ethnicity) were assessed for their contribution to $\mathrm{CHD}$ in the sampled population. No significant differences in the documented phenotypes were observed between males and females.

2.3. Genotyping APOB rs11279109 Polymorphism. From $5 \mathrm{ml}$ of whole blood, total genomic DNA was isolated with proteinase K digestion and salting out [32]. The rs11279109 polymorphism was analyzed by direct amplification of a $93 \mathrm{bp}$ target sequence employing the polymerase chain reaction (PCR) as described previously [31, 33]. A 4\% 3:1 Nusieve: agarose gel prestained with ethidium bromide $(10 \mathrm{mg} / \mathrm{ml})$ was used to resolve the PCR products by electrophoresis for one hour at $200 \mathrm{~V}$ and $100 \mathrm{~mA}$. Bands were visualized under UV and documented using Syngene Digital documentation system (Synoptics Ltd., UK), and the fragment size of the products was determined by comparison to a $123 \mathrm{bp}$ DNA ladder using Gene tools software (version 4.00). Different genetic models based on the obtained genotypes were devised.

2.4. Statistical Analysis. Results were expressed as mean \pm SEM and percentages where appropriate. Nonparametric analysis was performed where appropriate. Logarithmic transformation was applied where appropriate. HardyWeinberg equilibrium (HWE) was tested using the webbased calculator available at http://www.tufts.edu/, which confirmed the population to be in equilibrium. The genetic association was analyzed and controlled for age, sex, BMI, subethnicity, smoking status, and total cholesterol using the SNPassoc package from R software (R Stats Package, Version 3.3.0). The results are expressed as odds ratio (OR) with $95 \%$ confidence intervals (CI). All other statistical analyses were performed using SPSS software (Version 22; SPSS Inc., Chicago, IL, USA). Power calculation on the sample size 
was estimated using the statistical software package StatCalc (version 7.1.2.0; Epi InfoTM, Atlanta GA, USA). A power $>80 \%$ at alpha $=0.05$ was achieved in this study assuming an average OR of 2.5 and minor allele frequency of $7 \%$.

\section{Results}

3.1. Assessment of Risk Factors to CHD. Modifiable and nonmodifiable (age, sex, ethnicity, and family history) risk factors of the CHD patients $(n=372)$ compared with those of the control group $(n=363)$ are presented in Table 1 . No significant differences in the frequency distribution of sex, age, and BMI between the CHD patients and their controls were observed. Significant differences in the ethnicity of the two groups were observed in which the percentage of Kuwaiti patients of Arab ancestry was significantly higher $(P<0.001)$ among the CHD patients than the controls.

3.2. Genetic Association of $A P O B$ rs11279109 with the Association of Common Risk Factors and CHD. The most frequent genotype for $A P O B$ signal peptide polymorphism was the II genotype: $51.9 \%$ for the CHD patients and $60.9 \%$ for the controls (Table 2). However, the frequency of the $D$ allele in the CHD patients (0.32) was found to be higher than that of the $I$ allele (0.68) as well as higher than that in the controls where the frequency of the $D$ allele was 0.23 . Genotype and allele frequencies for the rs11279109 were found to be in HWE $(P>0.05)$ for the controls; however, a significant deviation $(P=0.015)$ was observed in the CHD group $(n=372)$ in which the proportion of the $D D$ genotype was found to be higher in Arab Bedouins (21.2\%) as compared to the other groups (Table 3). Genotype distribution for rs11279109 for all other risk factors assessed showed no significant differences $(P>0.05)$.

Multivariate logistic regression analysis, in which $\mathrm{CHD}$ was the dependent variable and the independent variables were the environmental risk factors, was used to investigate the contribution of the $D D$ genotype in the presence of the common risk factors to increase the risk to CHD in Kuwaitis and to assess their ORs. A summary of the results is presented in Table 4. The significant predictors of CHD in this model were smoking status $(P<0.001)$, medical history of diabetes mellitus $(P<0.001)$, high cholesterol level $(P=0.002)$, and family history of cardiac diseases $(P=0.024)$ after adjusting for the confounding variables (age and sex). The chance of having CHD was estimated to be 6.69 times higher for patients who ever smoked than those who never smoked, 5.73 times more for patients having positive medical history of diabetes mellitus, 1.85 times more for patients with positive medical history of high cholesterol, and 1.69 times higher among patients having positive family history of cardiac diseases than those who did not. Statistically significant associations with increased odd ratios for CHD was also observed for the $A P O B$ rs 11279109 polymorphism in which an $\mathrm{OR}=2.43$ was observed for the DD genotype.
TABLE 1: Distribution of common risk factors analyzed between the CHD patients and controls in the Kuwaiti population $(n=735)$.

\begin{tabular}{|c|c|c|}
\hline Variable & $\begin{array}{c}\text { CHD patients } \\
n=371 \\
n(\%)\end{array}$ & $\begin{array}{c}\text { Controls } \\
n=363 \\
n(\%)\end{array}$ \\
\hline \multicolumn{3}{|l|}{ Sex } \\
\hline Male & $246(66.1)$ & $228(62.8)$ \\
\hline Female & $126(33.9)$ & $135(37.2)$ \\
\hline \multicolumn{3}{|l|}{ Age (years) } \\
\hline$<40$ & $38(10.2)$ & $45(12.4)$ \\
\hline $40-49$ & $73(19.6)$ & $79(21.8)$ \\
\hline $50-59$ & $103(27.7)$ & $118(32.5)$ \\
\hline$\geq 60$ & $158(42.5)$ & $121(33.3)$ \\
\hline Mean \pm SD & $55.9 \pm 13.0$ & $54.2 \pm 12.8$ \\
\hline \multicolumn{3}{|l|}{ BMI $\left(\mathrm{kg} / \mathrm{m}^{2}\right)$} \\
\hline$<25$ & $76(20.4)$ & $67(18.8)$ \\
\hline $25-<30$ & $131(35.2)$ & $133(37.4)$ \\
\hline$\geq 30$ & $165(44.4)$ & $156(43.8)$ \\
\hline Mean \pm SD & $29.6 \pm 6.1$ & $30.1 \pm 6.9$ \\
\hline \multicolumn{3}{|l|}{ Ethnicity* } \\
\hline Arab & $156(41.9)$ & $173(48.1)$ \\
\hline Bedouin Arab & $95(25.5)$ & $18(5.0)$ \\
\hline $\mathrm{HU}$ & $24(6.5)$ & $92(25.6)$ \\
\hline Iranian & $97(26.1)$ & $77(21.4)$ \\
\hline \multicolumn{3}{|l|}{ Smoking status* } \\
\hline Nonsmoker & $252(67.9)$ & $338(93.1)$ \\
\hline Ex-smoker & $57(15.4)$ & $3(0.3)$ \\
\hline Current smoker & $62(16.7)$ & $22(6.1)$ \\
\hline \multicolumn{3}{|c|}{ Medical history of hypertension* } \\
\hline Yes & $205(55.1)$ & $157(43.3)$ \\
\hline \multicolumn{3}{|c|}{ Medical history of high cholesterol* } \\
\hline Yes & $172(46.2)$ & $102(28.1)$ \\
\hline \multicolumn{3}{|c|}{ Medical history of high triglycerides } \\
\hline Yes & $59(15.9)$ & $33(9.1)$ \\
\hline \multicolumn{3}{|c|}{ Medical history of diabetes mellitus* } \\
\hline Yes & $197(53.0)$ & $62(17.1)$ \\
\hline \multicolumn{3}{|c|}{ Family history of cardiac diseases } \\
\hline Yes & $103(27.7)$ & $66(18.2)$ \\
\hline
\end{tabular}

TABle 2: Genotype distribution of the $A P O B$ signal peptide polymorphism among the CHD patients $(n=372)$ and controls $(n=363)$ sampled in this study.

\begin{tabular}{lccc}
\hline APOB signal peptide & $\begin{array}{c}\text { CHD patient } \\
(n=372) \\
n(\%)\end{array}$ & $\begin{array}{c}\text { Controls } \\
(n=363) \\
n(\%)\end{array}$ & $\begin{array}{c}\text { Total } \\
(n=735) \\
n(\%)\end{array}$ \\
\hline II & $193(51.9)$ & $221(60.9)$ & $414(56.3)$ \\
ID & $118(31.7)$ & $117(32.2)$ & $235(32)$ \\
DD & $61(16.4)$ & $25(6.9)$ & $86(11.7)$ \\
\hline
\end{tabular}


TABLE 3: Association of the risk factors with the $A P O B$ signal peptide polymorphism in the Kuwaiti population investigated in this study $(n=735)$.

\begin{tabular}{|c|c|c|c|c|}
\hline Variable & $\begin{array}{c}\mathrm{II} \\
n=414 \\
n(\%)\end{array}$ & $\begin{array}{c}\text { Genotypes } \\
\text { peptide pol } \\
\text { ID } \\
n=235 \\
n(\%)\end{array}$ & $\begin{array}{c}\mathrm{DD} \\
n=86 \\
n(\%)\end{array}$ & ${ }^{*} P$ value \\
\hline Sex & & & & 0.692 \\
\hline Male & $264(55.7)$ & $151(31.9)$ & $59(12.4)$ & \\
\hline Female & $150(57.5)$ & $84(32.2)$ & $27(10.3)$ & \\
\hline BMI $\left(\mathrm{kg} / \mathrm{m}^{2}\right)$ & & & & 0.511 \\
\hline$<25$ & $77(53.8)$ & $44(30.8)$ & $22(15.4)$ & \\
\hline $25-<30$ & $145(54.9)$ & $88(33.3)$ & $31(11.7)$ & \\
\hline$\geq 30$ & $190(59.2)$ & $98(30.5)$ & $33(10.3)$ & \\
\hline Ethnicity & & & & 0.015 \\
\hline Arab & $192(58.4)$ & $102(31.0)$ & $35(10.6)$ & \\
\hline Bedouin Arab & $51(45.1)$ & $38(33.6)$ & $24(21.2)$ & \\
\hline $\mathrm{HU}$ & $71(61.2)$ & $38(32.8)$ & $7(6.0)$ & \\
\hline Iranian & $98(56.3)$ & $56(32.2)$ & $20(11.5)$ & \\
\hline Medical history of T2DM & & & & 0.803 \\
\hline No & $269(56.5)$ & $154(32.4)$ & $53(11.1)$ & \\
\hline Yes & $145(56.0)$ & $81(31.3)$ & $33(12.7)$ & \\
\hline Medical history of hypertension & & & & 0.986 \\
\hline No & $211(56.6)$ & $119(31.9)$ & $43(11.5)$ & \\
\hline Yes & $203(56.1)$ & $116(32.0)$ & $43(11.9)$ & \\
\hline Medical history of high cholesterol & & & & 0.616 \\
\hline No & $264(57.3)$ & $147(31.9)$ & $50(10.8)$ & \\
\hline Yes & $150(54.7)$ & $88(32.1)$ & $36(13.2)$ & \\
\hline Medical history of high triglycerides & & & & 0.637 \\
\hline No & $358(55.7)$ & $209(32.5)$ & $76(11.8)$ & \\
\hline Yes & $56(60.9)$ & $26(28.2)$ & $10(10.9)$ & \\
\hline Family history of cardiac diseases & & & & 0.814 \\
\hline No & $316(55.8)$ & $182(32.2)$ & $68(12.0)$ & \\
\hline Yes & $98(58.0)$ & $53(31.3)$ & $18(10.7)$ & \\
\hline
\end{tabular}

3.3. Genetic Modeling of $A P O B$ rs11279109 and CHD. Four different genetic models (Table 5) were devised to demonstrate the independent association of the $A P O B$ rs11279109 polymorphism with CHD in Kuwaiti patients after adjusting for sex, BMI, and as well as the identified common risk factors in this study including ethnicity, smoking status, and medical history of hypercholesterolemia. Due to missing data in total cholesterol and BMI $(n=67)$ in some CHD patients and controls, the number of samples analyzed in these models was 336 in $\mathrm{CHD}$ patients and 332 controls. A statistically significant association of the $D$ alleles and $D D$ genotype remained significant $(P<0.01)$ in four genetic models implicating its status as a "risk" allele. Only the over-dominant model was nonsignificant $(P>0.05)$ for the $D D$ genotype. The highest $O R$ ratio of $2.69(P=0.0009)$ for the $D D$ genotype was observed in the codominant model.

\section{Discussion}

This study extensively analyzed known risk factors for CHD in addition to a commonly studied genetic polymorphism, $A P O B$ rs11279109, among a sample of Kuwaiti natives $(n=735)$. The results from this study confirmed and further characterized previously reported risk factors in addition to newly identified risk factors and estimated their risk in the CHD patients $(n=372)$ sampled from the Kuwaiti population. In the current study, the observed statistically significant association between smoking $(P<0.001)$, hypocholesteremia $(P<0.001)$, and hypertriglyceridemia $(P<0.01)$ with $\mathrm{CHD}$ is in agreement with other studies reported for different populations [19, 24, 34-39].

The statistically significant association of ethnicity $(P<$ $0.001)$ and the known risk factors $(P<0.005)$, such as smoking (32.3\%; OR of 6.69), hypertension (55.1\% of CHD 
TABLE 4: Significant independent risk factors associated with CHD selected by the multivariate logistic regression analysis $(\mathrm{CHD}$ patients $=372$ and controls $=363)$.

\begin{tabular}{|c|c|c|}
\hline Variables & Odds ratio (adjusted) & ${ }^{\mathrm{a}} 95 \% \mathrm{CI}$ \\
\hline \multicolumn{3}{|l|}{$\begin{array}{l}A P O B \text { signal peptide } \\
\text { polymorphism }\end{array}$} \\
\hline II (reference group) & 1.00 & \\
\hline ID & 1.14 & $0.77-1.70$ \\
\hline $\mathrm{DD}$ & 2.43 & $1.34-4.41$ \\
\hline $\begin{array}{l}\text { Smoking status } \\
\text { Ever smoked* }\end{array}$ & 6.69 & $3.93-11.39$ \\
\hline $\begin{array}{l}\text { Medical history of } \\
\text { diabetes mellitus } \\
\text { Yes* }\end{array}$ & 5.73 & $3.77-8.71$ \\
\hline $\begin{array}{l}\text { Medical history of } \\
\text { high cholesterol } \\
\text { Yes }\end{array}$ & 1.85 & $1.24-2.76$ \\
\hline $\begin{array}{l}\text { Family history of } \\
\text { cardiac diseases } \\
\quad \text { Yes }\end{array}$ & 1.69 & $1.08-2.63$ \\
\hline
\end{tabular}

TABle 5: Statistical comparison of $A P O B$ rs11279109 genotype distribution $(n=668)$ in different genetic models between Kuwaiti CHD patients and controls after controlling for age, sex, BMI, ethnicity, smoking status, and medical history of hypercholesterolemia.

\begin{tabular}{lccc}
\hline Model & $\begin{array}{c}\text { Controls } \\
(n=336)\end{array}$ & $\begin{array}{c}\text { CHD patients } \\
(n=332)\end{array}$ & OR (95\% CI) \\
\hline Codominant & & & \\
$\quad$ II & $204(61.4 \%)$ & $174(51.8 \%)$ & 1 \\
ID & $104(31.3 \%)$ & $108(32.1 \%)$ & $1.24(0.88-1.76)$ \\
DD & $24(7.2 \%)$ & $54(16.1 \%)$ & $2.69(1.57-4.61)$ \\
Dominant & & & 1 \\
II & $204(61.4 \%)$ & $174(51.8 \%)$ & $1.51(1.1-2.08)$ \\
ID + DD & $128(38.6 \%)$ & $162(48.2 \%)$ & 1 \\
Recessive & & & $2.49(1.48-4.2)$ \\
II + ID & $308(92.8 \%)$ & $282(83.9 \%)$ & $1.5(1.19-1.89)$ \\
DD & $24(7.2 \%)$ & $54(16.1 \%)$ & $336(68.8 \%)$ \\
Additive & $332(30.4 \%)$ & $330)$
\end{tabular}

CHD: coronary heart disease; OR: odds ratio; CI: confidence interval. $P$ value for all models was less than 0.01 .

patients), medical history of T2DM (53.1\%; OR of 5.73), hypercholesterolemia (OR of 1.85), and family history of CHD (OR of 1.69) in addition to the newly identified $A P O B$ rs11279109 DD genotype (OR of 2.43), all contribute to the increased risk of CHD possibly through the development of different mechanisms leading to arthrosclerosis as a result of LDL oxidation. Increased cholesterol and TG levels have been shown to lead to the development of fibrotic plaques within the walls of the arteries [40] and to increase amounts of atherogenic lipoproteins such as LDL particles [41] and smaller TG-rich lipoproteins [42]. Although no statistically significant association $(P>0.05)$ was observed with regard to dyslipidemia and increased risk to CHD in this study, the 1.88-fold increase of hypercholesterolemia and the higher statistically significant association of the $D D$ genotype at the $A P O B$ signal peptide locus may implicate the role of this polymorphism in increasing the risk to CHD independently. It has been suggested that the $A P O B$ rs11279109 DD genotype results in a $66 \%$ reduction in the translocation of the $A P O B-100$ from the endoplasmic reticulum along with the increased hydrophobicity [33] that may result in slower transfer of the $A P O B-100$ and formation of LDL particles. The slow transfer and possible increased deposition of LDL due to a diet high in fat may cause an accumulation of LDLs in the vessels subjecting them to increased oxidation. No statistically significant association $(P>0.05)$ was found between the $D D$ genotype and cigarette smoking despite its 6 -fold increase in the risk to $\mathrm{CHD}$ among the studied population. However, the statistically significant association $(P<0.001)$ of the $D D$ genotype (OR 2.69) remained after adjusting for moking suggesting independent contribution from both risk factors in the mechanism of developing arthrosclerosis. Hypertension may also contribute to this mechanism through the pathophysiologic mechanisms that link hypertension with lipids and other metabolic disorders that eventually lead to CHD [43]. Despite the lack of association between the $A P O B$ rs11279109 with hypertension and dyslipidemia in this study, the role of other polymorphisms at the $A P O B$ gene locus or other loci may be contributing to this pathogenesis [19]. T2DM was demonstrated to be a significant risk factor (OR 5.73) for CHD which is in agreement with several studies that compared the CHD risk in T2DM patients as compared with nondiabetic subjects $[8,19,44]$.

Several studies have indicated that a positive family history of cardiac disease increases the risk of CHD [9, 45, 46]. In the present study, $27.7 \%$ of $\mathrm{CHD}$ patients had a positive family of cardiac diseases. Statistical analysis revealed a highly statistically significant association between $\mathrm{CHD}$ patients and positive family history of cardiac disease $(P=$ 0.002 ), and the risk of CHD is 1.67 times higher among individuals having positive family history of cardiac diseases compared to those with no family history. Myers and others found that the association between positive family history and CHD reflects either shared genetic predisposition or shared environmental habits [45]. This also applies to the studied population in this cohort as the majority of the samples were of Arab Bedouin or Persian ancestry (Table 1). Both these ethnic groups have similar cultural practices of consanguinity and nutrition high in fat. Ethnicity was also found to be significantly $(P<0.001)$ associated with CHD among the sampled Kuwaiti population, particularly among those from Bedouin Arab $(n=95,25.5 \%)$ and Iranian origins $(n=97 ; 26.1 \%)$ in comparison to the control group. In addition, HWE was deviated with regard to genotype distribution in the patient group only in which the homozygote DD genotype was in excess for the Arab Bedouin ethnic 
group (21.2\%, $P=0.015)$. These findings suggest that due to consanguinity the frequency of the $\mathrm{D}$ allele increased in the gene pool of these ethnic groups. In addition to other cultural practices, nutrition known to be very high in fat, differences in the structure of the LDL particles, and increased frequency of the $D D$ genotype at the $A P O B$ locus increased the risk for $\mathrm{CHD}$ in Kuwaiti Arab Bedouins. However, the association of $A P O B$ rs11279109 polymorphism, with increased risk for $\mathrm{CHD}$, remained significant $(P<0.001)$ even after adjusting for ethnicity and in fact increased the risk of carriers of the $D D$ genotype from 2.34 to 2.69 for the codominant model and 2.49 for the recessive model implicating that it as an additional nonmodifiable risk factor for CHD.

The genotype frequencies reported in this cohort were found to be similar to other reports. For example, the observed frequencies for the $A P O B$ signal peptide polymorphism (D:0.23, I:0.77) for the control group $(n=363)$ were similar to those reported in other populations $[26,30,46,47]$. The observed frequencies for the CHD patients $(n=372)$ (D:0.32, I:0.68) were also similar to those for the CHD patients reported for other populations [48]. The strong association and significant increase in developing $\mathrm{CHD}$ for the $D D$ genotype carriers in the Kuwaiti population strongly suggest their role as a "risk" allele in which its contribution to the development of arthrosclerosis may be independent of other risk factors. The effect of ethnicity of the genotype distribution and its relation to $\mathrm{CHD}$ risk in the Kuwaiti population were evaluated by stratification analysis (Supplementary Table 1) which confirmed the need for adjusting for ethnicity in the multivariate analysis. A more than two and a half fold increase in developing CHD for the $D D$ genotype remained even after adjusting for ethnicity and other risk factors including age, sex, BMI, smoking, and history of increased lipid levels. The $A P O B$ rs11279109 polymorphism and its association with lipid levels have demonstrated its effect on plasma lipid levels implicating the $I$ allele in decreasing TG levels [26]. This further supports the "risk" role of the D allele in increasing the risk for CHD. Therefore, it is strongly recommended that this polymorphism is tested when estimating the genetic risk score for CHD.

The limitations in this study was mainly related to the sample size although a power $>80 \%$ at alpha $=0.05$ was achieved (assuming an average OR of 2.5 and minor allele frequency of 7\%). However, further support to the findings reported in the cohort is warranted. Other limitations included lack of actual data on lipid profile, sugar, and blood pressure values as the patient's profiles were normal as a result of being under medication for a long period of time. However, medical history was recorded from their files which made it possible to assess the risk factors using multivariate analysis. Another limitation was unavailable serum apoB protein levels.

\section{Conclusion}

Several studies have attempted to investigate the association of various genetic markers at several gene loci with the pathogenesis of CHD in different populations and ethnic groups. Studies investigating the possible association of various $A P O B$ polymorphisms with specific metabolic disorders or syndromes reported inconsistent findings as well as some conflicting conclusions, very likely as a result of ethnicity. The results presented revealed a statistically significant association of the $A P O B$ rs11279109 polymorphisms with the increased risk to develop CHD among the Kuwaiti population which has not been reported previously. This encourages the need to further assess the role of this SNP and identify the role of other SNPs at different loci in the pathogenesis of CHD independent of the known common risk factors that are specific in the ethnic group of the studied population.

\section{Abbreviations}

$\begin{array}{ll}\text { ANOVA: } & \text { Analysis of variance } \\ \text { APOB: } & \text { Apolipoprotein B gene } \\ \text { APOB-SP: } & \text { Apolipoprotein B signal peptide } \\ \text { ApoE: } & \text { Apolipoprotein E gene } \\ \text { BMI: } & \text { Body mass index } \\ \text { CABG: } & \text { Coronary artery bypass grafting } \\ \text { CHD: } & \text { Coronary heart disease } \\ \text { DALYs: } & \text { Death and disability-adjusted life years } \\ \text { DM: } & \text { Diabetes mellitus } \\ \text { DNA: } & \text { Deoxyribonucleic acid } \\ \text { GWAS: } & \text { Genome-wide association studies } \\ \text { HD: } & \text { Heart disease } \\ \text { HDL: } & \text { High-density lipoprotein } \\ \text { HDL-C: } & \text { High-density lipoprotein cholesterol } \\ \text { HC: } & \text { Hypercholesterolemia } \\ \text { HTG: } & \text { Hypertriglyceridemia } \\ \text { HWE: } & \text { Hardy-Weinberg equilibrium } \\ \text { LDL: } & \text { Low-density lipoprotein } \\ \text { LDL-C: } & \text { Low-density lipoprotein cholesterol } \\ \text { mRNA: } & \text { Messenger ribonucleic acid } \\ \text { PCR: } & \text { Polymerase chain reaction } \\ \text { PTCA: } & \text { Percutaneous transluminal coronary } \\ \text { SEM: } & \text { angioplasty } \\ \text { SNPs: } & \text { Standard error of the mean } \\ \text { SPSS: } & \text { Single nucleotide polymorphisms } \\ \text { TC: } & \text { Statistical Package for the Social Sciences } \\ \text { TG: } & \text { Total cholesterol } \\ \text { T2DM: } & \text { Triglycerides } \\ \text { VLDL: } & \text { Type 2 diabetes mellitus } \\ \text { VNTR: } & \text { Very low-density lipoproteins } \\ \text { UNI ANOVA: } & \text { Uniriable number tandem repeats } \\ \text { UV: } & \text { Ultraviolet rays. } \\ & \end{array}$

\section{Data Access}

The authors welcome any request for additional data and documentations regarding the results from this study. Genetic data may be made available; however, no identifiers will be provided as per patient rights for confidentiality. 


\section{Conflicts of Interest}

The authors declare that there is no conflict of interests.

\section{Authors' Contributions}

Suzanne A. Al-Bustan prepared the project proposal and study design, supervised the molecular genetic studies and phenotypic documentation, supervised the data analysis, and drafted the manuscript. Fatma G. Ismael carried out the sample and data collection, genotyping, and some data analysis and participated in writing the manuscript. Ahmad Al-Serri performed most of the statistical analysis and genetic models and participated in writing the manuscript. Ibrahim Al-Rashdan facilitated and supervised the sample collection and documentation of the clinical and phenotypic data and assisted with the study. All the authors have read and approved the final manuscript.

\section{Acknowledgments}

The authors extend their deepest appreciation and gratitude to Mrs. Babitha G. Annice for her assistance with the genotyping methods, to the technical staff at the Kuwait Chest Hospital and Al-Ameri Hospital for their assistance with the blood collection and medical data, and to all the participants in this study. The authors would also like to acknowledge the valuable review and editing kindly done by Professor Olusegun A. Mojiminiyi and Dr. Martha Thomoson. This research was partly funded by Kuwait University Research Sector, Projects YS06/09 and SL05/03.

\section{Supplementary Materials}

Table S1. Stratification analysis of the genotype distribution for the $A P O B$ signal peptide polymorphisms between $\mathrm{CHD}$ and controls stratified according to subethnicity among the studied Kuwaiti population $(n=668)$. (Supplementary materials)

\section{References}

[1] R. Beaglehole, R. Bonita, R. Horton et al., "Priority actions for the non-communicable disease crisis," The Lancet, vol. 377, no. 9775, pp. 1438-1447, 2011.

[2] A. Al-Adsani, A. Memon, A. Peneva, and G. Baidas, "Clinical epidemiology of acute myocardial infarction in Kuwait," Acta Cardiologica, vol. 55, no. 1, pp. 17-23, 2000.

[3] Kuwait Ministry of Health Annual Report, Health Indicators of the State of Kuwait, Kuwait Ministry of Health, Kuwait, 2014.

[4] K. I. Sanakaranarayanan, R. Chakraborty, and E. A. Boerwinkle, "Ionizing radiation and genetic risks. VI. Chronic multifactorial diseases: a review of epidemiological and genetical aspects of coronary heart disease, essential hypertension and diabetes mellitus," Mutation Research, vol. 436, no. 1, pp. 21-57, 1999.

[5] S. Yusuf, S. Hawken, S. Ounpuu et al., "Effect of potentially modifiable risk factors associated with myocardial infraction in 52 countries (the INTERHEART study): case-control study," The Lancet, vol. 364, no. 9438, pp. 937-952, 2004.
[6] A. O. Akanji, N. Abdella, and A. O. Mojimmiyi, "Determinants of glycated LDL levels in nondiabetic and diabetic hyperlipidamic patients in Kuwait," Clinica Chimica Acta, vol. 317, no. 1-2, pp. 171-176, 2002.

[7] A. N. Al-Isa, "Changes in body mass index (BMI) and prevalence of obesity among Kuwaitis 1980-1994," International Journal of Obesity and Related Metabolic Disorders, vol. 21, no. 12, pp. 1093-1099, 1997.

[8] H. H. Al Khalaf, B. Lach, A. Allam, A. AlKhani, S. A. Alrokayan, and A. Abouseekhra, "The p53/p21 DNA damage-signaling pathway is defective in most meningioma cells," Journal of Neuro-Oncology, vol. 83, no. 1, pp. 9-15, 2007.

[9] S. A. Al-Bustan, M. Alkhalaf, I. Al-Rashdan et al., "Apolipoprotein E, CI and B gene polymorphisms in a sample of patients with coronary heart disease in the Kuwait population," Medical Principles and Practice, vol. 18, no. 4, pp. 294-299, 2009.

[10] A. Al-Serri, F. G. Ismael, S. A. Al-Bustan, and I. Al-Rashdan, "Association of the insertion allele of the common ACE gene polymorphism with type 2 diabetes mellitus among Kuwaiti cardiovascular disease patients," Journal of the ReninAngiotensin-Aldosterone System, vol. 16, no. 4, pp. 910-916, 2015.

[11] N. Dzimiri, B. F. Meyer, S. S. Hussain, C. Basco, B. Afrane, and Z. Halees, "Relevance of apolipoprotein E polymorphism for coronary artery disease in the Saudi population," Archives of Pathology \& Laboratory Medicine, vol. 123, no. 12, pp. 1241-1245, 1999.

[12] J. P. Casas, J. Cooper, G. J. Miller, A. D. Hingorani, and S. E. Humphries, "Investigating the genetic determinants of cardiovascular disease using candidate genes and metaanalysis of association studies," Annals of Human Genetics, vol. 70, no. 2, pp. 145-169, 2006.

[13] N. J. Samani, J. Erdmann, A. S. Hall et al., "Genome wide association analysis of coronary artery disease," New England Journal of Medicine, vol. 357, no. 5, pp. 445-453, 2007.

[14] CARDIoGRAMplusC4D Consortium, P. Deloukas, S. Kanoni et al., "Large-scale association analysis identifies new risk loci for coronary artery disease," Nature Genetics, vol. 45, no. 1, pp. 25-33, 2013.

[15] L. Zhang, F. Yuan, P. Liu et al., "Association between PCSK9 and $L D L R$ gene polymorphisms with coronary heart disease: case-control study and meta-analysis," Clinical Biochemistry, vol. 46, no. 9, pp. 727-732, 2013.

[16] S. Berkinbayev, M. Rysuly, A. Mussayev et al., "Apolipoprotein gene polymorphisms (APOB APOC111, APOE) in the development of coronary heart disease in ethnic groups of Kazakhstan," Journal of Genetic Syndromes \& Gene Theraphy, vol. 5, no. 2, p. 216, 2014.

[17] J. Z. Zhang, Y. Y. Zheng, Y. N. Yang et al., "Association between apolipoprotein $\mathrm{B}$ gene polymorphisms and the risk of coronary heart disease (CHD): an update meta-analysis," Journal of the Renin-Angiotensin-Aldosterone System, vol. 16, no. 4, pp. 827-837, 2015.

[18] J. S. Kanu, Y. Gu, S. Zhi et al., "Single nucleotide polymorphism rs3774261 in the AdipoQ gene is associated with the risk of coronary heart disease (CHD) in Northeast Han Chinese population: a case-control study," Lipids in Health and Disease, vol. 15, no. 1, p. 6, 2016.

[19] L. Larifla, K. E. Beaney, L. Foucan et al., "Influence of genetic risk factors on coronary heart disease occurrence in AfroCaribbeans," Canadian Journal of Cardiology, vol. 32, no. 8, pp. 978-985, 2016. 
[20] J. F. Ferguson, G. J. Matthews, R. R. Townsend et al., "Candidate gene association study of coronary artery calcification in chronic kidney disease: finding from the CRIC study (chronic renal insufficiency cohort)," Journal of the American College of Cardiology, vol. 62, no. 9, pp. 789-798, 2013.

[21] B. D. Blackhart, E. M. Ludwig, V. R. Pierotti et al., "Structure of the human apolipoprotein B gene," Journal of Biological Chemistry, vol. 261, no. 33, pp. 15364-15367, 1986.

[22] E. H. Ludwig, W. Friedl, and B. J. Mccarthy, "High-resolution analysis of a hypervariable region in the human apolipoprotein B gene," American Journal of Human Genetics, vol. 45, no. 3, pp. 458-464, 1989.

[23] K. Aalto-Setala, H. Gylling, E. Helve et al., "Genetic polymorphism of the apolipoproteins B gene locus influences serum LDL cholesterol level in familial hypercholesterolemia," Human Genetics, vol. 82, no. 4, pp. 305-307, 1989.

[24] M. Delghandi, R. Thangarajah, M. Nilsen et al., "DNA polymorphisms of the apolipoprotein B gene (Xbal, EcoRI, and MspI RFLPs) in Norwegians at risk of atherosclerosis and healthy controls," Acta Cardiologica, vol. 54, no. 4, pp. 215-225, 1999.

[25] J. F. Felix, J. P. Bradfield, C. Monnereau et al., "Genome-wide association analysis identifies three new susceptibility loci for childhood body mass index," Human Molecular Genetics, vol. 25, no. 2, pp. 389-403, 2015.

[26] S. A. Al-Bustan, M. A. Alnaqeeb, B. G. Annice, G. A. Ebrahim, and T. M. Refai, "Genetic association of APOB polymorphisms with variation in serum lipid profile among the Kuwait population," Lipids in Health and Disease, vol. 13, no. 1, p. 157, 2014.

[27] S. Visvikis, L. Chan, G. Siest, P. Drouin, and E. Boerwinkle, "An insertion deletion polymorphism in the signal peptide of the human apolipoprotein B gene," Human Genetics, vol. 84, no. 4, pp. 373-375, 1990.

[28] E. Boerwinkle, S. S. Lee, R. Butler, V. N. Schumaker, and L. Chan, "Rapid typing of apolipoprotein B DNA polymorphisms by DNA amplification. Association between Ag epitopes of human apolipoprotein B-100, a signal peptide insertion/deletion polymorphism, and a 3'flanking DNA variable number of tandem repeats polymorphism of the apolipoprotein B gene," Atherosclerosis, vol. 81, no. 3, pp. 225-232, 1990.

[29] D. A. Demarchi, A. J. Marcellino, M. A. de Basualdo et al., "Apolipoprotein B signal peptide polymorphism distribution among south Amerindian populations," Human Biology, vol. 71, no. 6, pp. 995-1000, 1999.

[30] A. Horvath, V. Chorbov, B. Zaharova, and V. Ganev, "Five polymorphisms of the apolipoprotein $\mathrm{B}$ gene in healthy Bulgarians," Human Biology, vol. 75, no. 1, pp. 69-80, 2003.

[31] S. A. Al-Bustan, A. E. Al-Serri, B. G. Annice, M. A. Alnaqeeb, and G. A. Ebrahim, "Re-sequencing of the APOA1 promoterr region and the genetic association of the $-75 \mathrm{G}>\mathrm{A}$ polymorphism with increased cholesterol and low density lipoprotein levels among a sample of the Kuwaiti population," BMC Medical Genetics, vol. 14, no. 1, p. 90, 2013.

[32] S. A. Miller, D. D. Dykes, and H. F. Polesky, "A simple saltingout procedure for extracting DNA from human nucleated cells," Nucleic Acids Research, vol. 16, no. 3, p. 1215, 1988.

[33] C. F. Xu, M. Tikkanen, J. Huttunen et al., "Apolipoprotein B signal peptide insertion/deletion polymorphism is associated with Ag epitopes and involved in the determination of serum triglyceride levels," Journal of Lipid Research, vol. 31, no. 7, pp. 1255-1261, 1990.
[34] M. Muros and C. Rodriguez-Derrer, "Apolipoprotein E polymorphism influence on lipids, apolipoproteins and $\mathrm{Lp}(\mathrm{a})$ in a Spanish population underexpressing apo E4," Atherosclerosis, vol. 121, no. 1, pp. 13-21, 1996.

[35] I. Kawachi, G. A. Colditz, F. E. Speizer et al., "A prospective study of passive smoking and coronary heart disease," Circulation, vol. 95, no. 10, pp. 2374-2379, 1997.

[36] K. L. Khoo, H. Tan, Y. M. Liew, J. P. Deslypere, and E. Janus, "Lipids and coronary heart disease in Asia," Atheresclerosis, vol. 169, no. 1, pp. 1-10, 2003.

[37] U. Keil, "Coronary artery disease: the role of lipids, hypertension and smoking," Basic Research in Cardiology, vol. 95, Supplement 1, pp. 152-158, 2000.

[38] M. M. Al-Nozha, Y. Y. Al-Marzou, M. R. Afrah et al., "Smoking in Saudi Arabia and its relation to coronary artery disease," Journal of the Saudi Heart Association, vol. 21, no. 3, pp. 169-176, 2009.

[39] L. M. Baynouna, A. D. Revel, N. J. Nagelkerke et al., “Association of cardiovascular risk factors in $\mathrm{Al}$ Ain, United Arab Emirates," Cardiovascular Diabetology, vol. 8, no. 1, p. 21, 2009.

[40] J. E. McLaren, D. R. Michael, T. G. Ashlin, and D. P. Ramji, "Cytokines, macrophage lipid metabolism and foam cells: implications for cardiovascular disease therapy," Progress in Lipid Research, vol. 50, no. 4, pp. 331-347, 2011.

[41] M. A. Austin, M. C. King, K. M. Vranizan, B. Newman, and R. Krauss, "Inheritance of low-density lipoprotein subclass patterns: results of complex segregation analysis," American Journal of Human Genetics, vol. 43, no. 6, pp. 838-846, 1988.

[42] G. M. Reaven, Y. D. Chen, J. J. Jeppesen, P. Maheux, and R. M. Krauss, "Insulin resistance and hyperinsulinemia in individuals with small, dense low density lipoprotein particles," Journal of Clinical Investigation, vol. 92, no. 1, pp. 141-146, 1993.

[43] G. Assmann, R. Carmena, P. Cullen et al., "Coronary heart disease: reducing the risk: a worldwide view. International task force for the prevention of coronary heart disease," Circulation, vol. 100, no. 18, pp. 1930-1938, 1999.

[44] M. Laakso, "Cardiovascular disease in type 2 diabetes: challenge for treatment and prevention," Journal of Internal Medicine, vol. 249, no. 3, pp. 225-235, 2001.

[45] R. H. Myers, D. K. Kiely, L. A. Cupples, and W. B. Kannel, "Parental history is an independent risk factor for coronary artery disease: the Framingham study," American Heart Journal, vol. 120, no. 4, pp. 963-969, 1990.

[46] E. Boerwinkle, S. H. Chen, S. Visvikis, C. L. Hanis, G. Siest, and L. Chan, "Signal peptide-length variation in human apolipoprotein B gene. Molecular characteristics and association with plasma glucose levels," Diabetes, vol. 40, no. 11, pp. 15391544, 1991.

[47] A. Hamsten, G. Walldius, A. Szamosi, G. Dahlen, and U. de Faire, "Relationship of angiographically defined coronary artery disease to serum lipoproteins and apolipoproteins in young survivors of myocardial infarction," Circulation, vol. 73, no. 6, pp. 1097-1110, 1986.

[48] P. R. Turner, P. J. Talmud, S. Visvikis, C. Ehnholm, and L. Tiret, "DNA polymorphisms of the apoprotein B gene are associated with altered plasma lipoprotein concentrations but not with perceived risk of cardiovascular disease: European atherosclerosis research study," Atherosclerosis, vol. 116, no. 2, pp. 221-234, 1995. 


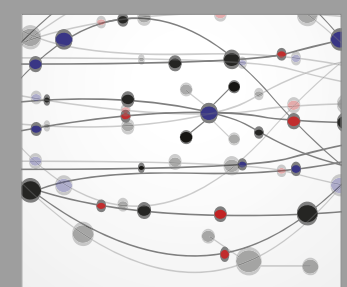

The Scientific World Journal
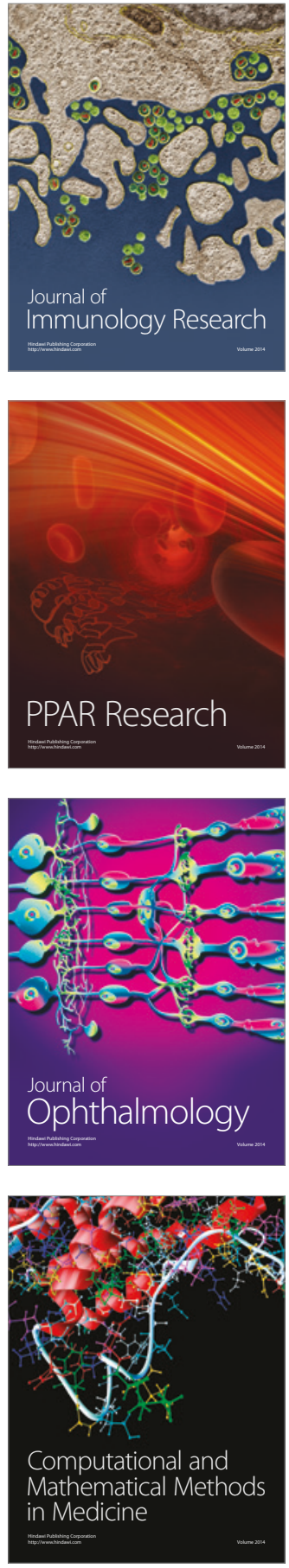

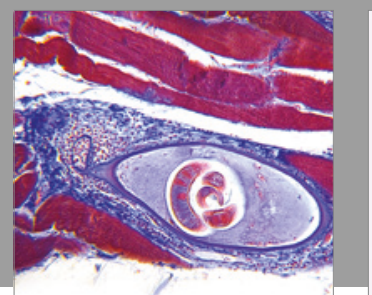

Gastroenterology Research and Practice
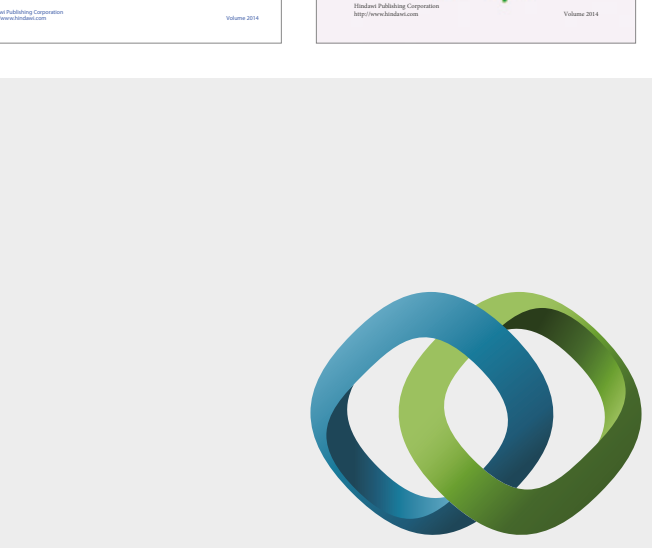

\section{Hindawi}

Submit your manuscripts at

https://www.hindawi.com
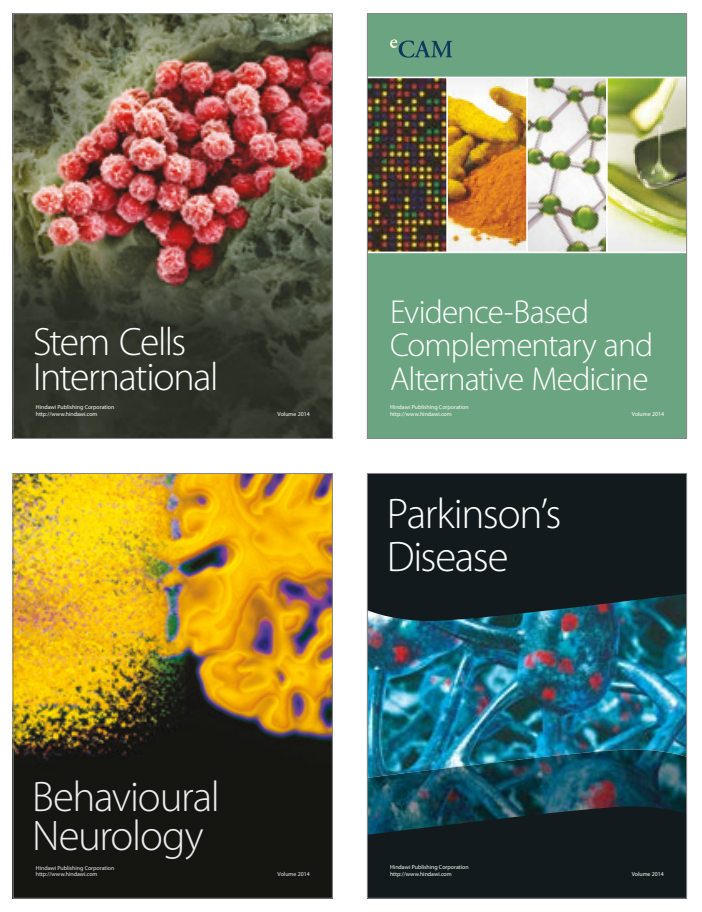
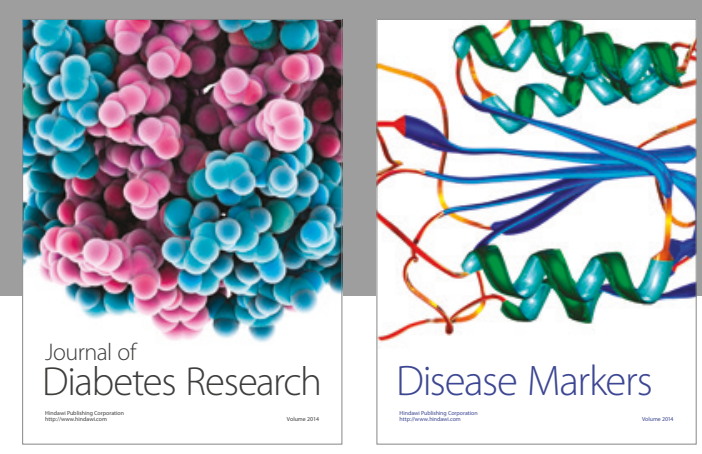

Disease Markers
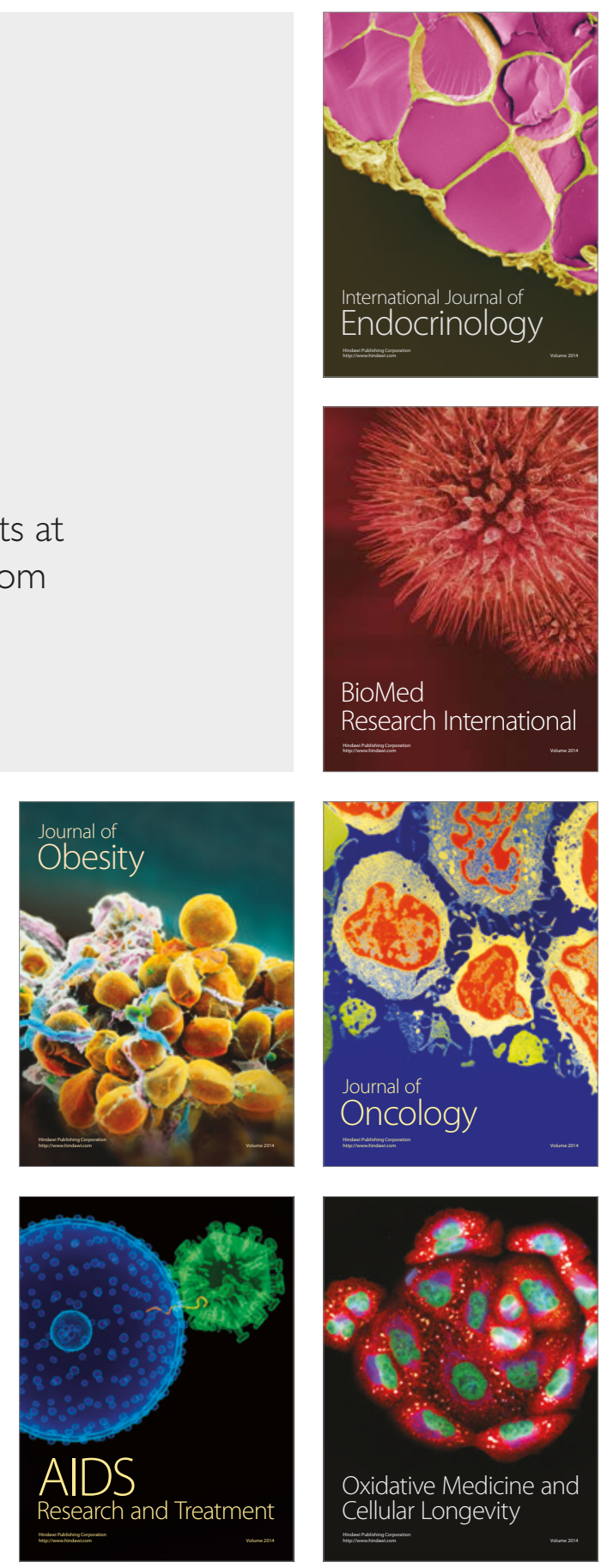